\title{
Novel Angular and Polarization Independent Band-Stop Frequency Selective Surface for Ultra-Wide Band Applications
}

\author{
Aybike KOCAKAYA, Sibel ÇIMEN, Gonca ÇAKIR \\ Dept. of Electronics and Communications Engineering, Kocaeli University, Turkey \\ adirikol@kocaeli.edu.tr, sibelgunduz@kocaeli.edu.tr, gonca@kocaeli.edu.tr
}

Submitted May 11, 2018 / Accepted November 2, 2018

\begin{abstract}
A novel compact band-stop frequency selective surface (FSS) with angular and polarization stability performance for ultra-wide band (UWB) applications is presented in this paper. The designed unit cell consists of a square loop element and a crossed dipole with a ring slot element. The novel unit cell size is miniaturized to $0.047 \lambda \times 0.047 \lambda$, where $\lambda$ is free-space wavelength corresponding to the lowest frequency of the UWB band. The $-3 \mathrm{~dB}$ bandwidth of the proposed FSS is between $3.05 \mathrm{GHz}$ and $10.73 \mathrm{GHz}$ frequencies which covers the whole UWB band as defined by FCC. Due to compact size of unit cell, the proposed FSS has good angular stability up to $60^{\circ}$ incident angles both perpendicular (TE) and parallel (TM) polarization. The maximum resonance frequency deviation is $1.75 \%$ for TE polarization. In addition, the proposed FSS has excellent stable resonant frequency. The designed FSS is fabricated and experimental measurements are performed. There is a good consistency between numerical simulations and measurement results.
\end{abstract}

\section{Keywords}

Angular stability, frequency selective surface, ultrawide band, miniaturization

\section{Introduction}

Frequency selective surfaces are essentially two-dimensional infinite periodic structures [1]. In recent years, frequency selective surfaces have become an interesting subject for many researchers. Frequency selective surfaces can be utilized to filter some specific frequencies in civil or military applications aiming to improve the front-to-back ratio of the antennas, reduce the out-of-band RCS of the antennas, shield the electromagnetic wave and suppress the interference from other communication systems [3-11]. It is difficult to design band-stop FSS with ultra-wideband angularly stable and sharp roll-off transition filtering response. The response of FSS is not only dependent on frequency, but also, it is affected by the electromagnetic wave polarization and incidence of angle.
Since the US Federal Communications Commission (FCC) released the frequency range of $3.1 \mathrm{GHz}$ to $10.6 \mathrm{GHz}$ for unlicensed usage in 2002, UWB communication technology has become very popular among researchers. In UWB communication systems, ultra-short pulses are used for transmission and reception, and the spectrum spreads to a very wide frequency range [2]. Thus, a very large bandwidth is required for UWB applications. UWB systems with low power spectral density can use the frequency spectrum reserved for other communication systems without interference. For this reason, various UWB microwave components have been studied especially UWB filters like FSSs.

Many UWB-FSS studies are proposed in the literature. Multilayer dielectric substrates are used to obtain a broad bandwidth and a sharper filtering response. This causes a bulky structure and an increase of fabrication cost. In [12], dual layered FSS with low profile is designed for UWB antenna reflector. Measurements exhibit that proposed FSS transmission curve is under $-10 \mathrm{~dB}$ between $3.5 \mathrm{GHz}$ and $11.45 \mathrm{GHz}$ frequency range. In [13], a fourlayered UWB band stop FSS is presented. At each layer, the unit cell contains different length of square loop to obtain broad bandwidth from $10 \mathrm{GHz}$ to $16.1 \mathrm{GHz}$. UWBFSS design exhibiting band stop filter from $2.5 \mathrm{GHz}$ to $14 \mathrm{GHz}$ is presented in [14]. The UWB-FSS unit cell is placed between two dielectric substrates. It is angularly stable up to $40^{\circ}$ incident angle for TE and TM polarization. There are many studies about single layer UWB band stop FSS. Most of them are broadband, but they are not suitable for bandwidth defined as FCC UWB standards exactly. In [15], the unit cell consisting of cross dipole and ring metallic shapes is designed for shielding over UWB. According to the transmission response of FSS, the shielding bandwidth is between $6.5 \mathrm{GHz}$ to $14 \mathrm{GHz}$ for $20 \mathrm{~dB}$ attenuation. In [16], the unit cell consisting of a square loop and a cross dipole printed on one side of a single layer substrate is proposed for UWB applications. This FSS has band-stop filter response over frequency range from $7 \mathrm{GHz}$ to $14 \mathrm{GHz}$. In many researches, the single layer UWB FSS techniques with unit cell printed on two sides of the substrate are investigated. The unit cell printed on both sides of a substrate is used, the sharp roll-off transition filter 
response can be obtained. However, it is difficult to achieve flat top filtering response at the out of band. In [17], a novel band stop FSS is presented and its unit cell consists of two metallic spirals with different lengths printed on both sides of a dielectric substrate. It has a stable transmission response with respect to various incident angles. In [18], a miniaturized FSS with wide stop band characteristics is presented and its unit cell consists of garland shape etched on both two sides of a dielectric substrate for UWB applications. For different angle of incidences, angularly stable frequency response is obtained for both TE and TM polarization modes. Therefore, it is aimed for designing a novel band stop FSS that has angularly stable frequency response through the whole UWB range.

In this paper, a novel single layer band-stop UWBFSS is presented. Compared to other studies in the literature, it has the smallest unit cell with single layer design so far. To operate over ultra-wide band, a combination of a square loop, a cross dipole and ring slot shapes has been used. The designed FSS is printed on a single side of Arlon AD600 substrate. The FSS is designed to exhibit the stable angular transmission response for both TE and TM polarizations of incident angle up to $60^{\circ}$ under $-3-\mathrm{dB}$ transmission.

\section{Designed FSS Configuration}

There are four main types of geometrical forms of the FSS unit cell exhibiting their own frequency response characteristics as shown in Fig. 1 [1]. The combination of these unit cells can be used to generate new elements with a range of specific properties, such as elements for multiband FSSs, polarization independent FSSs and miniaturized element, and so on.

In this study, a new compact single layer band stop FSS with angular and polarization stability performance in the entire UWB is designed. The designed single layer FSS with broad bandwidth is the most challenging subject at the design process. A multi-layer FSS structure can be useful to obtain a broadband response. However, using of a multilayer structure results in an increase of the size and fabrication costs of the FSS. To change geometrical form of the unit cell, to reduce the inter-element spacing and to increase the thickness of dielectric layer can be used to construct a broadband single layer FSS filter. A new unit cell can be constructed by using the resonant elements and/or non-resonant elements to form a broadband FSS. To obtain an angularly stable and broadband response, FSS consisting of two resonant elements such as a square loop and a crossed dipole with a ring slot is proposed (Fig. 2).

The proposed design is set to cover the ultra-wideband (UWB) frequency range of $3.1-10.6 \mathrm{GHz}$ approved by the Federal Communications Commission (FCC). When a square loop element is used alone, a bandwidth larger than the range of $3.1-10.6 \mathrm{GHz}$ is obtained. In other words, when this type unit cell is used, the waves outside this frequency range are also blocked. In this study, it is aimed

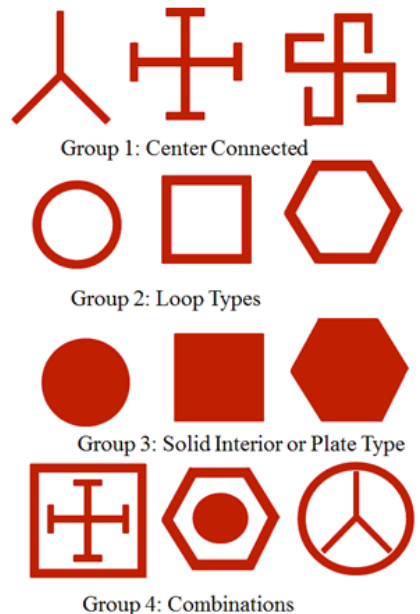

Fig. 1. Typical element types [1].

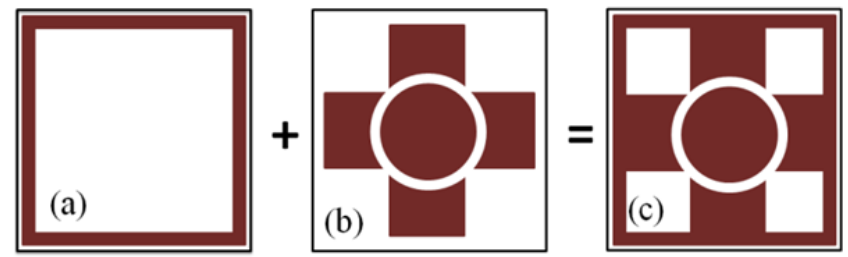

Fig. 2. Design steps: (a) Square loop element of the FSS, (b) crossed dipole with ring slot element of the FSS, (c) geometry of the proposed FSS unit cell.

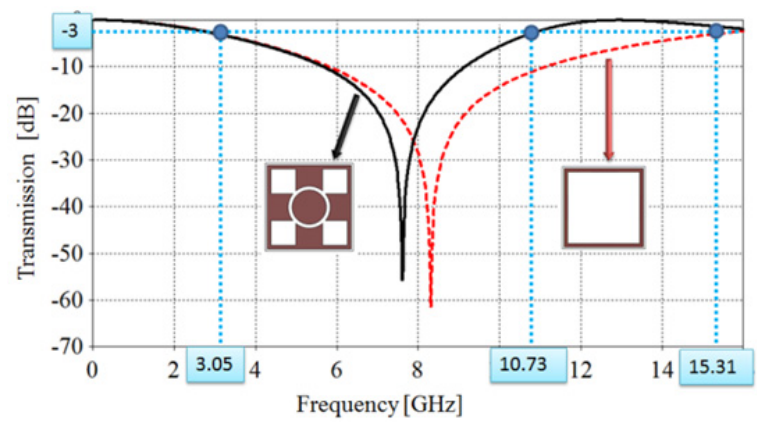

Fig. 3. Transmission behaviors of the square loop and the designed FSS at normal incidence.

to design a FSS that will block only the UWB extending from $3.1 \mathrm{GHz}$ to $10.6 \mathrm{GHz}$. Two resonant elements have been suitably integrated to form a new element in order to set the bandwidth to the range of 3.1-10.6 GHz.

The outer square loop dimension determines the lower cut-off frequency of the FSS. The cross dipole with ring slot element added to the square loop causes the resonant frequency shift towards lower frequency side. According to transmission line theory, band-stop FSS is modeled as a serial LC circuit when it is illuminated by electromagnetic wave. The resonant frequency of the FSS is $f_{\mathrm{r}}=1 /\left[2 \pi(L C)^{1 / 2}\right] . L$ represents the inductance of the metallic strip, and its value is proportional to the length of the metal strips. $C$ represents the capacitance between the slot of metallic strips. When a square loop FSS is illuminated by the electromagnetic wave, it acts as an inductive component in series with a capacitive component. Adding cross dipole element to unit cell geometry means adding an in- 
ductor to the equivalent circuit. The resonant frequency shifts toward higher frequency region. Forming of a slot on the cross dipole means adding of a capacitor to the FSS equivalent circuit. So forming of a slot on the cross dipole causes resonant frequency shifting towards lower frequency region. So that it is possible to design the FSS with the desired frequency response by suitably combining the different geometric shapes.

Physical dimensions of the unit cell used in this study are illustrated in Fig. 4(a). Figure 4(b) shows the whole structure of the FSS array. While the conductive surface is shown with a dark colored region, the other region shows a dielectric substrate. The geometrical symmetric nature will provide polarization independent operation. Table 1 gives dimensions of the proposed geometry.

The proposed structure is a simple single layer FSS printed on a substrate Arlon AD600 with a thickness $h=0.508 \mathrm{~mm}$ and a relative permittivity $\varepsilon_{\mathrm{r}}=6.15$ without a ground plane. Additionally, the dimension of the overall unit cell is $4.6 \times 4.6 \mathrm{~mm}^{2}$. The designed unit cell is very compact in size. The size of the unit cell is $0.047 \lambda \times 0.047 \lambda$, where $\lambda$ is free-space wavelength corresponding to the lowest frequency of the UWB band. The FSS should exhibit stable responses for larger incidence of angles. In this study, the purpose of using the miniaturization method is to eliminate the angular dependencies. Miniaturization of the unit cell removes the sensitivity of incidence angle variations. Based on Munk's FSS designing theory, the angular stability of the FSS is affected both the inter-element spacing and shape of the unit cell element. In general, large inter-element spacing leads to occurrence of grating lobes.

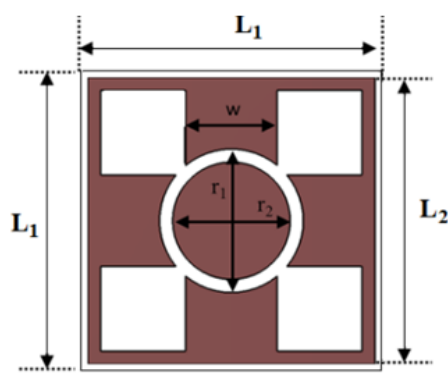

(a)

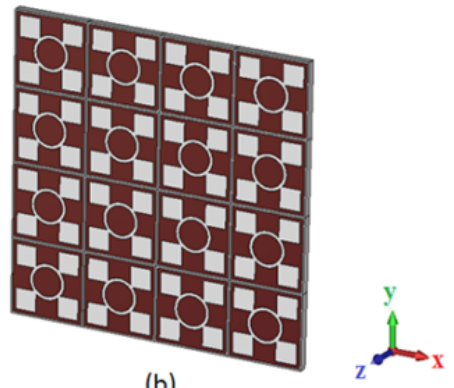

(b)

Fig. 4. Transmission behaviors of the square loop and the designed FSS at normal incidence.

\begin{tabular}{|l|l|l|l|l|}
\hline $\mathbf{L}_{\mathbf{1}}$ & $\mathbf{L}_{\mathbf{2}}$ & $\mathbf{r}_{\mathbf{1}}$ & $\mathbf{r}_{2}$ & $\mathbf{w}$ \\
\hline 4.6 & 4.4 & 2.2 & 1.8 & 1.4 \\
\hline
\end{tabular}

Tab. 1. Geometrical details of the proposed FSS (mm).

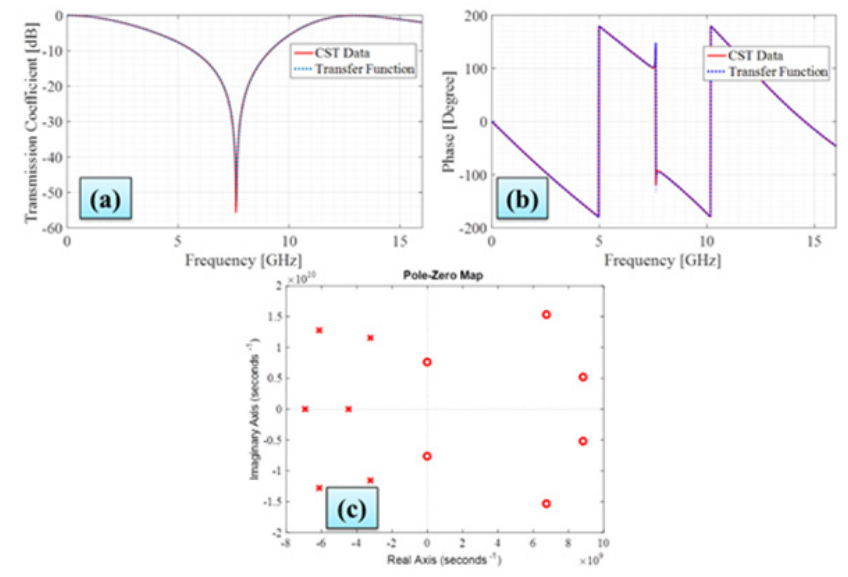

Fig. 5. CST analysis and estimated transfer functions comparison: a) transmission coefficients, (b) phase graphs, (c) locations of zeros and poles of the transfer function for the proposed FSS design.

Although small inter element spacing can improve the angular stability of FSSs, this effect is limited. Naturally, some types of elements have better angularly stable response like as cross dipole element. To increase the angular stability of the FSS with respect to the incident angle, the dimension of the unit cell is further reduced. Usually, the unit cell dimension should be a quarter of the wavelength at the resonance frequency for square loop geometry. In practice, FSS has a finite size and in order to achieve a desired frequency response, the finite FSS surface must contain sufficient numbers of element to act like an infinite FSS. Thus, the overall size of the FSS surface is large. To overcome this problem, miniaturized element FSSs are suggested [20], [21].

Since $D$ is the unit cell length, to prevent grating lobes, the following equation [1] should be satisfied.

$$
D<\frac{\lambda_{0}}{1+\sin \theta_{0}}
$$

where $\lambda_{0}$ is the wavelength in the free space and $\theta_{0}$ is the incident angle. As the incident angle increases the unit cell length $D$ should be smaller. For $60^{\circ}$ incident angle, $D$ should be smaller than $21.15 \mathrm{~mm}$ at resonant frequency.

Utilizing MATLAB code given in study [19], the optimal transfer coefficient and phase graphs by using S21 data of FSS (amplitude, phase, real and imaginary parts) via CST MWS is generated. The comparison of transmission coefficient, phase simulation graphs with the optimal transfer function and locations of zeros and poles of the transfer function for the proposed FSS design are shown in

$$
H(s)=\frac{0.5224 s^{6}-1.627 e^{10} s^{5}+3.561 e^{20} s^{4}-4.27 e^{30} s^{3}+3.429 e^{40} s^{2}-1.934 e^{40} s-8.957 e^{59}}{s^{6}-3.013 e^{10} s^{5}+6.686 e^{20} s^{4}+8.48 e^{30} s^{3}+7.7 e^{40} s^{2}+4.247 e^{50} s 8.96 e^{59}}
$$


Fig. 5. The optimal transfer function for the proposed FSS structure is obtained when the number of poles-zeros is equal to 6 as shown in Fig. 5. The estimated transfer function given in (2) has almost the same characteristic with CST result.

\section{Oblique Incidence Simulation Results for TE\&TM Polarization}

The simulation of the transmission responses is performed using the CST Microwave studio under the unit cell boundary conditions and Floquet modes. Conducting surfaces of the unit cell geometry are modelled as PEC (Perfect electric conductor) with zero thickness for simulation simplicity. Many parametric studies were simulated to achieve final unit cell geometry. Firstly, the numerical simulations have been implemented to investigate transmission response with different polarization modes respect to normal of the surface. The simulation of the transmission response is shown in Fig. 6 for TE and TM polarization modes. As it can be seen, the designed FSS provides stop band characteristics for a wide-band ranging $3.05 \mathrm{GHz}$ and $10.73 \mathrm{GHz}$ and has $7.5 \mathrm{GHz}$ resonant frequency. Also, the design FSS demonstrates identical transmission response for both TE and TM polarization because of its symmetrical geometry.

The simulations have been implemented for oblique incident angles up to $60^{\circ}$ both TE and TM polarization mode shown in Fig. 7(a) and Fig. 7(b). It is clearly understood that the proposed FSS behaves like as a stable band stop filter for oblique incidence. The transmission coefficients of designed FSS have a stable performance over the entire UWB frequency region for TE polarization. For TE polarization, the resonant frequency is remained almost the same under different oblique incidence and the bandwidth has increased. The fractional bandwidth is more than $100 \%$ with respect to resonant frequency. The increase in the angle of incidence wave causes the bandwidth to decrease for TM polarization. In all angles of incidence, the narrowest bandwidth is obtained for $60^{\circ}$ incident angles. Detailed data that contain the entire bandwidth analysis are given in Tab. 2. The designed FSS exhibits a stable resonant frequency at about $7.6 \mathrm{GHz}$ as the angle of incidence ranging from 0 to 60 degrees. In this table $f_{\mathrm{L}}, f_{\mathrm{R}}$ and $f_{\mathrm{H}}$ represent respectively lower cut-off frequency, resonant frequency and higher cut-off frequency.

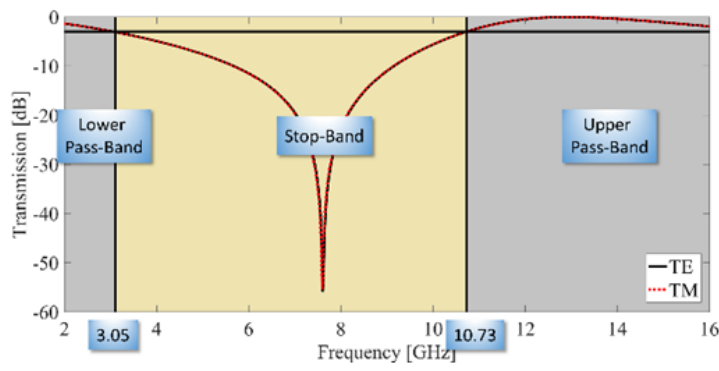

Fig. 6. Simulated result of the transmission coefficient.

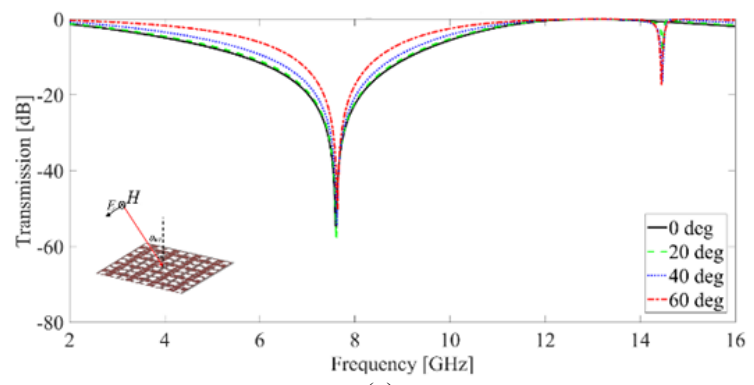

(a)

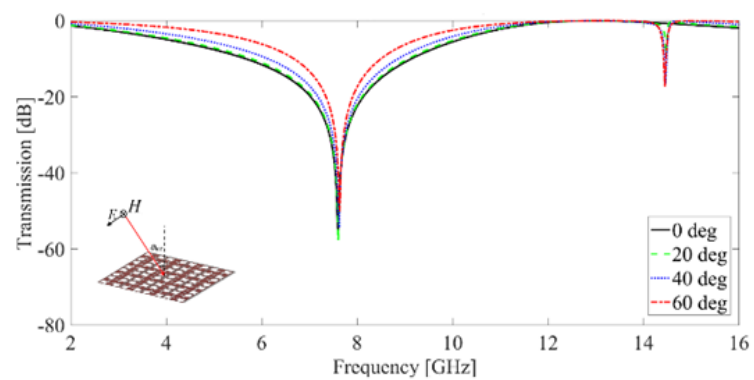

(b)

Fig. 7. Transmission coefficients at different incidence angles $\left(0^{\circ}, 20^{\circ}, 40^{\circ}\right.$ and $\left.60^{\circ}\right)$ : (a) for TE, (b) for TM.

\begin{tabular}{|c|c|c|c|c|}
\hline \multicolumn{5}{|c|}{ TE Polarization } \\
\hline \multirow{2}{*}{$\begin{array}{l}\text { Angle } \\
\text { (Degree) }\end{array}$} & \multicolumn{2}{|c|}{ Frequency (GHz) } & \multirow{2}{*}{\begin{tabular}{l}
$\begin{array}{l}\text { Resonant } \\
\text { Frequency } \\
(\mathbf{G H z})\end{array}$ \\
\multicolumn{1}{c}{$\mathbf{f}_{\mathrm{R}}$} \\
\end{tabular}} & \multirow{2}{*}{$\begin{array}{l}\text { Bandwidth } \\
(\%)\end{array}$} \\
\hline & $\mathbf{f}_{\mathrm{L}}$ & $\mathbf{f}_{\mathrm{H}}$ & & \\
\hline 0 & 3.05 & 10.73 & 7.60 & 101 \\
\hline 20 & 2.93 & 10.83 & 7.63 & 103 \\
\hline 40 & 2.55 & 11.01 & 7.68 & 110 \\
\hline 60 & 1.81 & 11.43 & 7.73 & 124 \\
\hline \multicolumn{5}{|c|}{ TM Polarization } \\
\hline 0 & 3.04 & 10.72 & 7.60 & 101 \\
\hline 20 & 3.19 & 10.64 & 7.60 & 98 \\
\hline 40 & 3.73 & 10.37 & 7.62 & 87 \\
\hline 60 & 4.86 & 9.81 & 7.63 & 64 \\
\hline
\end{tabular}

Tab. 2. Oblique incidence bandwidth analysis for TE and TM polarization.

\begin{tabular}{|c|c|c|c|c|}
\hline Angle & $\mathbf{0}^{\circ}$ & $\mathbf{2 0}^{\circ}$ & $\mathbf{4 0}^{\circ}$ & $\mathbf{6 0}^{\circ}$ \\
\hline $\begin{array}{c}\text { TE } \\
\text { polarization }\end{array}$ & 0 & $0.15 \%$ & $0.9 \%$ & $1.75 \%$ \\
\hline $\begin{array}{c}\text { TM } \\
\text { polarization }\end{array}$ & 0 & $0.15 \%$ & $0.15 \%$ & $0.48 \%$ \\
\hline
\end{tabular}

Tab. 3. Resonance frequency deviation according to angle of incidence (aoi).

The designed FSS provides stable resonance frequency with different polarization and angles. Resonant frequency deviation values are presented in Tab. 3 .

When the deviation values are compared to frequency for normal incidence both TE and TM polarization, it is observed that maximum amount of relative deviation is 


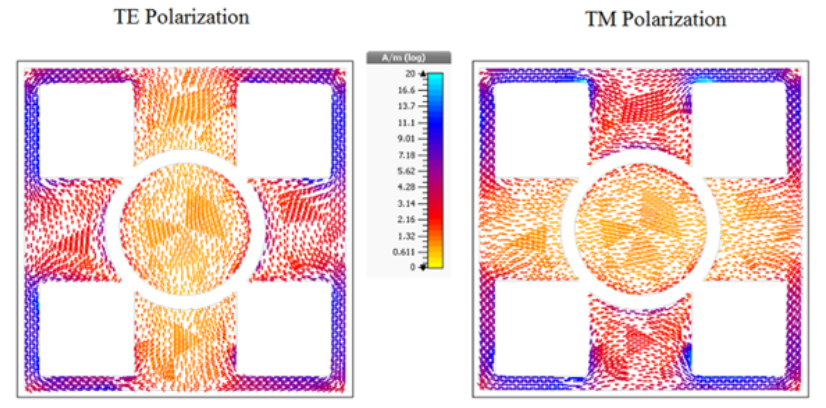

Fig. 8. Surface current distribution diagram at $7.6 \mathrm{GHz}$.

$1.75 \%$, for $60^{\circ}$ TE-polarized waves. Relative deviation is calculated as

$$
\Delta f=\left|\frac{f_{\mathrm{r}}-f_{\text {ang }}}{f_{\mathrm{r}}}\right| \times 100
$$

where $f_{\mathrm{r}}$ is the resonance frequency, $f_{\text {ang }}$ is the angular frequency, and $\Delta f$ is the relative frequency deviation.

Surface current distribution diagram at $7.6 \mathrm{GHz}$ is shown in Fig. 8. As seen from the figure, the current distributions are stronger on the horizontal arm of the cross dipole element in TE mode and the vertical arm of the cross dipole is active in TM mode.

\section{Fabrication and Measurement Results}

To validate the simulation results, designed FSS structure was fabricated and tested as shown in Fig. 9. The prototype of FSS was printed on single side of Arlon D600 substrate with $0.508 \mathrm{~mm}$ thickness. The FSS array consists of $43 \times 61$ element that its dimensions are approximately $297 \mathrm{~mm} \times 217 \mathrm{~mm}$. Experimental measurements are performed using two identical broad band waveguide horn antennas in a free space measurement setup at 3-meter anechoic chamber with $900 \mathrm{MHz}-20 \mathrm{GHz}$ frequency range. The broad band waveguide horn antennas operate from $1 \mathrm{GHz}$ to $18 \mathrm{GHz}$ with a nominal $11 \mathrm{~dB}$ gain. They have $244 \mathrm{~mm} \times 164 \mathrm{~mm}$ slot and $204 \mathrm{~mm}$ taper length. UWB horn

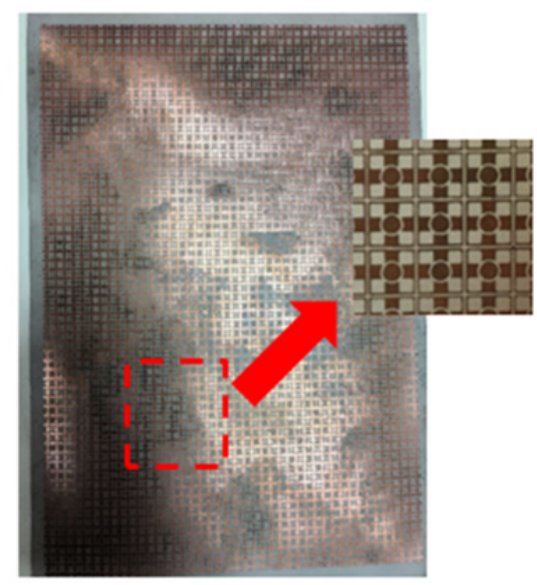

Fig. 9. Photo of the prototype FSS panel.

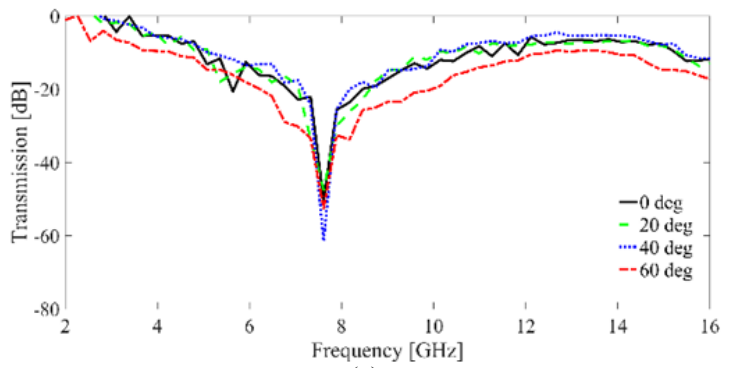

(a)

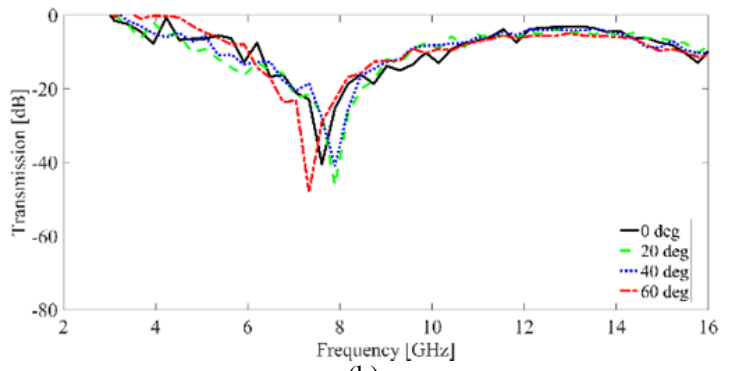

(b)

Fig. 10. Measurements of transmission coefficients at different incidence angles $\left(0^{\circ}, 20^{\circ}, 40^{\circ}\right.$ and $\left.60^{\circ}\right)$ for: (a) TE polarization (b) TM polarization.
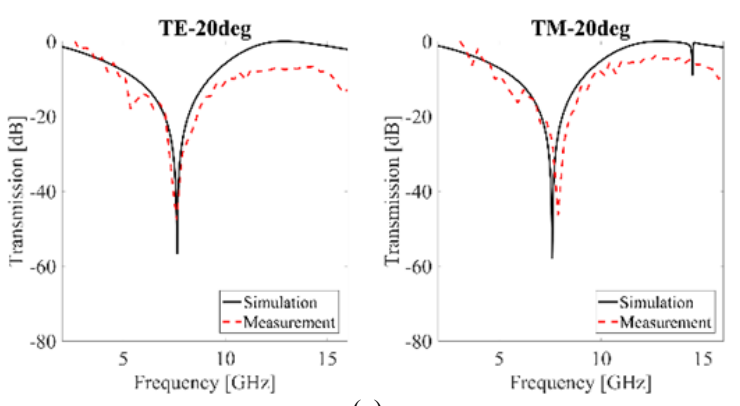

(a)
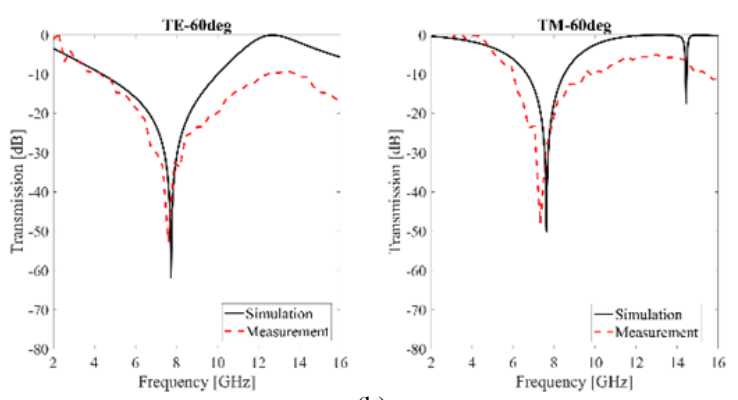

(b)

Fig. 11. Measured and simulated results at oblique incident angles of $20^{\circ}$ for (a) TE, (b) TM.

antennas were connected to the Rohde \& Schwarz ZVB 20 vector network analyzer (VNA) by a low-loss coaxial cable. The transmitting and receiving antennas were located on the line-of-sight direction at the same height and the same distance from the FSS panel.

Measurements of transmission coefficients under different oblique incident angles and polarizations are shown in Fig. 10(a) and (b). It can be evaluated that the stable transmission coefficients are obtained for different incident angles up to $60^{\circ}$ for both polarizations. Also the edge diffraction causes to the ripples of measurements. 


\begin{tabular}{|c|c|c|c|c|c|}
\hline $\begin{array}{c}\text { FSS } \\
\text { structure }\end{array}$ & Unit cell & $\varepsilon_{\mathrm{r}}[-]$ & $\begin{array}{c}\text { Number } \\
\text { of layers }\end{array}$ & $\begin{array}{c}\text { Bandwidth } \\
{[\mathbf{G H z}]}\end{array}$ & $\begin{array}{c}\text { Angle of } \\
\text { incidence }\end{array}$ \\
\hline $\begin{array}{c}\text { Structure in } \\
{[12]}\end{array}$ & $0.17 \lambda \times 0.17 \lambda$ & 4.4 & 2 & $3.5-11.45$ & - \\
\hline $\begin{array}{c}\text { Structure in } \\
{[14]}\end{array}$ & $0.046 \lambda \times 0.046 \lambda$ & 10.6 & 2 & $2.5-14$ & $40^{\circ}$ \\
\hline $\begin{array}{c}\text { Structure in } \\
{[17]}\end{array}$ & $0.66 \lambda \times 0.26 \lambda$ & 4.4 & Both sides & $6.5-14$ & - \\
\hline $\begin{array}{c}\text { Structure in } \\
{[18]}\end{array}$ & $0.19 \lambda \times 0.19 \lambda$ & 4.3 & Both sides & $7.04-10.55$ & $60^{\circ}$ \\
\hline $\begin{array}{c}\text { Structure in } \\
{[19]}\end{array}$ & $0.067 \lambda \times 0.67 \lambda$ & 2.2 & Both sides & $3.25-3.38$ & $80^{\circ}$ \\
\hline $\begin{array}{c}\text { The proposed } \\
\text { FSS }\end{array}$ & $0.047 \lambda \times 0.047 \lambda$ & 6.15 & One side & $3.05-10.73$ & $60^{\circ}$ \\
\hline
\end{tabular}

Tab. 4. Results of comparison to other FSSs.

Simulation data and measurement results were compared at each oblique angle incidence for both polarizations. With $20^{\circ}$ and $60^{\circ}$ incidence angle, comparison of the transmission coefficients simulation data and measurement results are as illustrated at Fig. 11(a) and (b) There is a good agreement between simulation data and measurement results.

There is a comparison table which compares the presented work with the earlier published similarly works (Tab. 4). As seen from Tab. 4, this FSS provides an angular stability up to $60^{\circ}$ with only one side layer.

\section{Conclusion}

In this study, a novel miniaturized frequency selective surface with ultra-wide stop band characteristics is presented. The $-3 \mathrm{~dB}$ bandwidth of the proposed FSS is between $3.05 \mathrm{GHz}$ and $10.73 \mathrm{GHz}$ frequencies and covers the whole UWB band as defined by FCC. Utilizing miniaturization, the stable resonant frequency and angularly stable transmission response is obtained under oblique incidence up to $60^{\circ}$. The presented FSS is a good candidate for UWB filtering applications.

\section{Acknowledgment}

The authors wish to acknowledge the assistance and support of The Scientific and Technological Research Council of Turkey (TUBITAK) for supporting this work (Project No: 215E101).

\section{References}

[1] MUNK, B. A. Frequency Selective Surfaces: Theory and Design. New York: John Wiley \& Sons; 2000. ISBN: 978-0-471-37047-5

[2] FEDERAL COMMUNICATIONS COMMISSION. First Report and Order. Revision of Part 15 of the Commission's Rule Regarding Ultra-Wideband Transmission Systems. Washington (DC). ET Docket 98153, FCC 02-48, Feb. 2002.

[3] ZABRI, N., CAHILL, R., SCHUCHINSKY, A. Polarisation independent resistively loaded frequency selective surface absorber with optimum oblique incidence performance. IET Microwaves, Antennas and Propagation, 2014, vol. 8, no 14, p. 1198-1203. DOI: 10.1049/iet-map.2014.0124

[4] RASPOPOUlOS, M., STAVROU, S. Frequency selective buildings through frequency selective surfaces. IEEE Transaction on Antennas and Propagation, 2011, vol. 59, no. 8, p. 2998-3005. DOI: 10.1109/TAP.2011.2158779

[5] SYED, I. S., RANGA, Y., MATEKOVITS, L., et al. A singlelayer frequency-selective surface for ultrawideband electromagnetic shielding. IEEE Transactions on Electromagnetic Compatibility, 2014, vol. 56, no. 6, p. 1404-1411. DOI: 10.1109/TEMC.2014.2316288

[6] ZHOU, H., QU, S., LIN, B., et al. Filter-antenna consisting of conical FSS radome and monopole antenna. IEEE Transactions on Antennas and Propagation, 2012, vol. 60, p. 3040-3045. DOI: 10.1109/TAP.2012.2194648

[7] KUSHWAHA, N., KUMAR, R. Design of slotted ground hexagonal microstrip patch antenna and gain improvement with FSS screen. Progress In Electromagnetics Research B, 2013, vol. 51, p. 177-199. DOI: 10.2528/PIERB13031604

[8] RAM KRISHNA, R. V. S., KUMAR, R. Slotted ground microstrip antenna with FSS reflector for high-gain horizontal polarisation. Electronics Letters, 2015, vol. 51, p. 599-600. DOI: 10.1049/el.2015.0339

[9] KUMAR, R., KUSHWAHA, N., RAM KRISHNA, R. V. S. Design of ultra wideband hexagonal patch slot antenna for highgain wireless applications. Journal of Electromagnetic Waves and Applications, 2014, vol. 28, no. 16, p. 2034-2048. DOI: $10.1080 / 09205071.2014 .954678$

[10] YANG, Y., ZHOU, H., WANG, X. H., et al. Low-pass frequency selective surface with wideband high-stop response for shipboard radar. Journal of Electromagnetic Waves and Applications, 2013, vol. 27, no. 1, p. 117-122. DOI: 10.1080/09205071.2013.739547

[11] WANG, W. T., GONG, S. X., WANG, X., et al. RCS reduction of array antenna by using bandstop FSS reflector. Journal of Electromagnetic Waves and Applications, 2009, vol. 23, p. 1505-1514. DOI: 10.1163/156939309789476473

[12] RANGA, Y., MATEKOVIS, L., WEILY, A. R., et al. A lowprofile dual-layer ultra-wideband frequency selective surface reflector. Microwave and Optical Technology Letters, 2013, vol. 55, p. 1223-1227. DOI: 10.1002/mop. 27583

[13] RADONIĆ, V., CRNOJEVIĆ-BENGIN, V., SCHOEMAN, D., et al. Multi-layer frequency selective surfaces with wideband response and their modelling. In 22nd Telecommunication Forum TELFOR. 2014, p. $757-7560 . \quad$ DOI: 10.1109/TELFOR.2014.7034517

[14] YAHYA, R., NAKAMURA, A., ITAMI, M. UWB frequency selective surfaces with angular stability and notched band at $5.5 \mathrm{GHz}$. In IEEE International Conference on Ubiquitous Wireless Broadband. Nanjing (China), 2016, p. 1-3. DOI: 10.1109/ICUWB.2016.7790451

[15] SOHAIL, I., RANGA, Y., ESSELLE, K. P., et al. Effective electromagnetic shielding over an ultra-wide bandwidth using a frequency selective surface. In Asia-Pacific Symposium on Electromagnetic Compatibility. Melbourne (VIC, Australia), 2013, p. 284-287. DOI: 10.1109/APEMC.2013.7360634

[16] CRUZ, R. S. M., D’ASSUNÇÃO, A. G., SILVA, P. H. F. A new FSS design proposal for UWB applications. In International Workshop on Antenna Technology. Lisbon (Portugal), 2010, p. 1-4. DOI: 10.1109/IWAT.2010.5464645

[17] LI, W. L., ZHANG, T., YANGI, G. H., et al. Novel frequency selective surfaces with compact structure and ultra-wideband response. In Asia-Pacific Symposium on Electromagnetic Compatibility. Singapore, 2012, p. 557-590. DOI: 10.1109/APEMC.2012.6238018 
[18] BAISAKHIYA, S., SIVASAMY, R., KANAGASABAI, M., et al. Novel compact uwb frequency selective surface for angular and polarization independent operation. Progress In Electromagnetics Research Letters, 2013, vol. 40, p. 71-79. DOI: 10.2528/PIERL13022707

[19] AZEMI, S. N., GHORBANI, K., ROWE, W. S. T. Angularly stable frequency selective surface with miniaturized unit cell. IEEE Microwave and Wireless Components Letters, 2015, vol. 25, no. 7, p. 454-456. DOI: 10.1109/LMWC.2015.2429126

[20] BAYATPUR, F., SARABANDI, K. Single-layer high-order miniaturized-element frequency-selective surfaces. IEEE Transactions on Microwave Theory and Techniques, 2008, vol. 56, no. 4, p. 774-781. DOI: 10.1109/TMTT.2008.919654

[21] CHIU, C.-N., CHANG, K.-P. A novel single-metal-layer miniaturized element frequency selective surface: concept and design. Journal of Electromagnetic Waves and Applications, 2010, vol. 24, p. 1545-1552. DOI: 10.1163/156939310792149579

\section{About the Authors ...}

Aybike KOCAKAYA was born in Sakarya, Turkey, in 1978. She received the B.S., M.S., and Ph.D. degrees in Electronics and Communication Engineering from Kocaeli University (KOU), Kocaeli, Turkey, in 2000, 2003, and
20018, respectively. She is a Research Assistant at the Microwave and Antennas Laboratory currently. Her research interests include frequency selective surfaces and design of UWB antennas.

Sibel ÇİMEN was born in Çanakkale, Turkey, in 1980. She received the B.S., M.S., and Ph.D. degrees in Electronics and Communication Engineering from Kocaeli University (KOU), Kocaeli, Turkey, in 2002, 2005, and 2009, respectively. From 2005 to 2009, she was a Research Assistant with the Microwave and Antennas Laboratory. Currently, she is an Associate Professor with the Electronics and Communication Engineering Department, KOU. Her research interests include numerical methods for planar structures, metamaterials, frequency selective surfaces, reflectarray antennas and design of UWB antennas and microstrip filters.

Gonca ÇAKIR received the B.S.E.E, M.S.E.E, and Ph.D. degrees in Electronics and Communication Engineering from Kocaeli University (KOU), Kocaeli, Turkey, in 1996, 1999, and 2004, respectively. Currently, she is a Professor with the Engineering Faculty, KOU. Her research interests include analytical and numerical methods for planar structures (transmission lines, circuits, and antennas), radars, RCS prediction techniques, and metamaterials. 